\title{
Environmental Earth Sciences progress report 2019 and outlook 2020
}

\author{
Barbara Kolditz ${ }^{1} \mathbb{D} \cdot$ Gunter Dörhöfer $^{2} \cdot$ Jim LaMoreaux ${ }^{3} \cdot$ Olaf Kolditz $^{4}$
}

Received: 9 February 2020 / Accepted: 28 April 2020 / Published online: 1 June 2020

(c) Springer-Verlag GmbH Germany, part of Springer Nature 2020

\begin{abstract}
This editorial provides a follow-up to the status report in Environmental Earth Sciences (EES) of 2017. It includes the refined aims and scope of the journal (see "Scope and shape"), honors the most cited papers contributing to the 2019 impact factor (IF) (see Most cited topics and papers), and provides information on the current status of EES (see "Progress report").
\end{abstract}

Keywords Environmental Earth Sciences (EES) $\cdot$ Most cited papers $\cdot$ Progress report $\cdot$ Scope

\section{Scope and shape}

Environmental Earth Sciences encompasses broad multidisciplinary fields in geoscientific research (Kolditz et al. 2018). The Editor's met in fall 2019 in Leipzig, Germany to discuss the aims and scope of the journal in the context of new developments in the research field. The year 2019 was remarkable concerning the "Climate Debate" in the public, science, and policy arenas. It is of utmost importance in the journal's scope with a focus on solid earth and related environmental impacts. For papers focusing on climate-atmosphere-surface processes we recommend more specialized journals in order to boost the visibility of those works.

"Environmental Earth Sciences is an international multidisciplinary journal concerned with innovative approaches and significant aspects of interaction between humans, natural resources or unique geographic zones, with emphasis on the solid earth. In pursuit of these topics, the geoscientific community is invited to contribute their knowledge and experience. Major disciplines include: hydrogeology, hydrochemistry, geochemistry, geophysics, engineering geology, natural resources management, environmental geography and soil science." (Scope was revised at the Editor's fall meeting 2019 in Leipzig.)

\footnotetext{
Barbara Kolditz

ees-editor@web.de

Leipzig, Germany

Brandenburg a.d.Havel, Germany

Tuscaloosa, USA

4 Leipzig/Dresden, Germany
}

In addition to the Editors revising the aims and scope, Springer has established a new website for EES. Latest articles from the journal are highlighted with a key figure or photo allowing readers to easily grasp contents and to attract their interest (Fig. 1).

\section{Most cited topics and papers}

"Word clouds" used in the 2017 editorial will continue to be used here to keep the continuity. Even though this procedure might not be acknowledged as a rigorous scientific approach - it provides interesting insight into the most cited topics. Paper titles of the 50 most cited articles in different time periods were used over all years since publication of EES in 2009. Published under other names previously, the journal changed its name to Environmental Earth Sciences (EES) in 2009. The size of the words corresponds to their frequency in the paper titles.

Figure 2 depicts temporal snapshots of word clouds: (a) from the current year 2019, (b) from a current impact factor relevant period and (c) over all years since publication of EES in 2009.

When inspecting the figures visually, we immediately notice that "China" is the key country of investigations; groundwater and landslide related topics are important for all time periods. The term "using" may stand for the application-oriented character of the journal; however we also observe a certain variety of highlighted key words: 
A

\section{恝 Springer}

You're seeing our new journal sites and we'd like your opinion, please send feedback

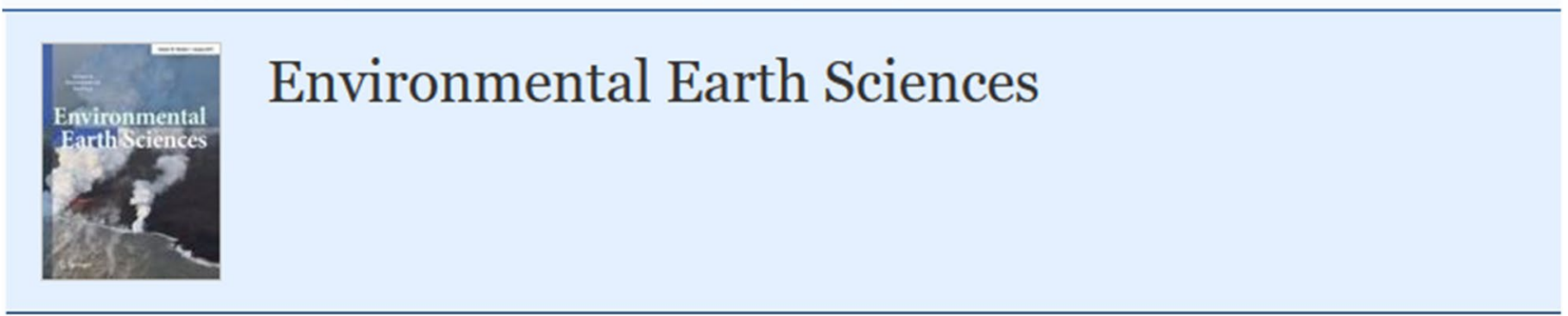

B

\section{Latest articles}

Comparison of logistic regression and neural network models in assessing geomorphic control on alluvial fan depositional processes (Calabria, southern Italy)

Federica Lucà \& Gaetano Robustelli

Original Article | Published: 26 December 2019

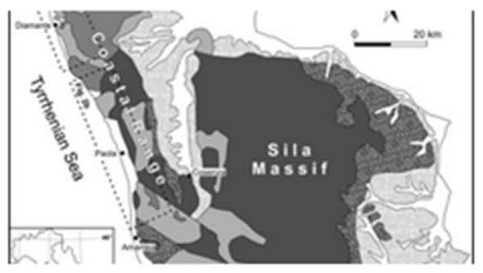

Land surface temperature relation with normalized satellite indices for the estimation of spatio-temporal trends in temperature among various land use land cover classes of an arid Potohar region using Landsat data

Aqil Tariq, Iqra Riaz ... Muhammad Rafiq

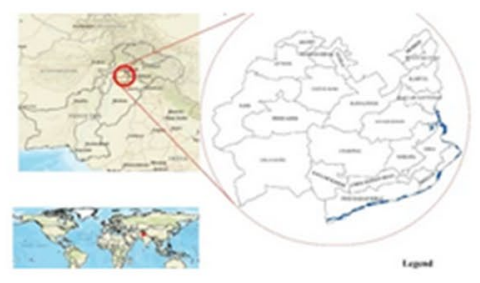

Original Article Published: 26 December 2019

Fig. 1 A glimpse of the new EES website: https://www.springer.com/journal/12665

- 2019: In addition to the common key words, "coal" and "water" belong to the most used words in the current year.

- 2017-2018: Two words are very prominent "assessment" and "susceptibility". The first term emphasizes increasing environmental impact studies, the latter is related to the risk of slides.

- 2009-2019: Taking all EES publication years into account "landslide" "GIS" "mapping" "CO2" belong to the most used words in paper titles. Geological $\mathrm{CO} 2$ sequestration (carbon capture and storage) was a major research area some time ago and will probably come back soon in the context of climate mitigation. Several topical collections have been dedicated to CCS in EES (Kharaka et al. 2010; Kühn et al. 2012; Liu et al. 2014; Senger et al. 2015).

As a part of the EES editorial synthesis, among the large number of excellent works, the most cited papers in 2019 starting from 2017 are highlighted here. This procedure corresponds to the calculation of a journal's impact factor for 2019. ${ }^{1}$ Please note, that the present editorial paper is not influencing the impact factor calculation and related selfcitations as all 2019 papers are published already.

\footnotetext{
$\overline{1}$ https://en.wikipedia.org/wiki/Impact_factor.
} 


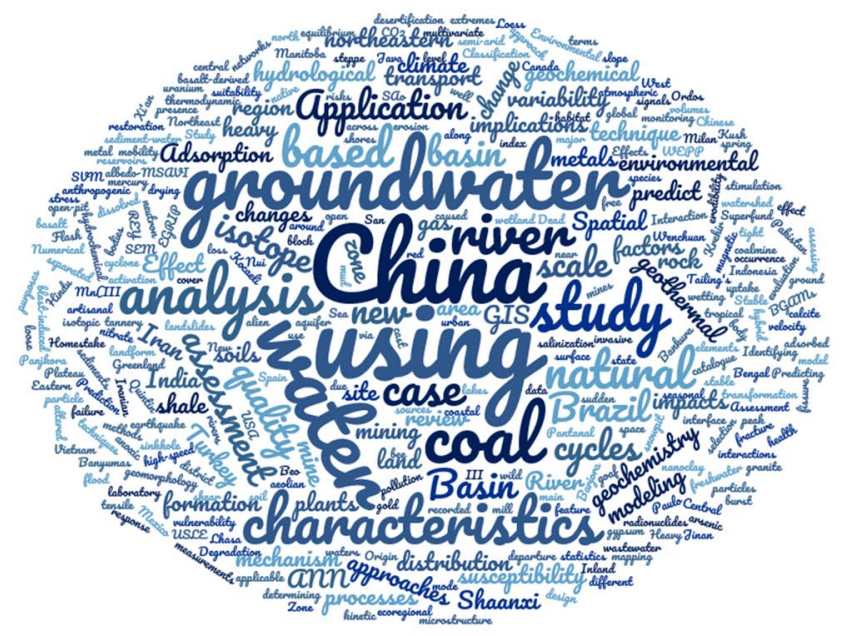

(a) 2019

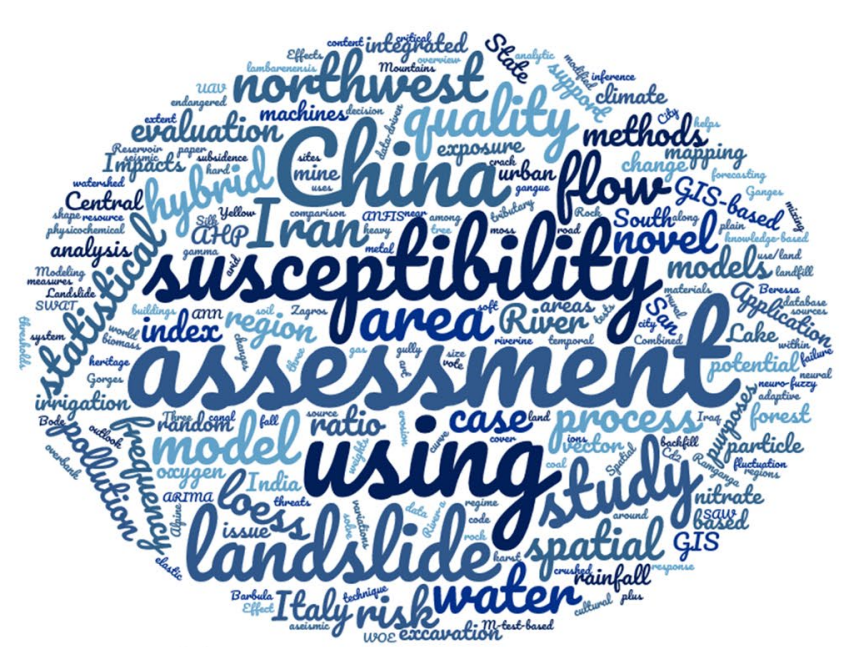

(b) 2017-2018 (impact factor 2019)

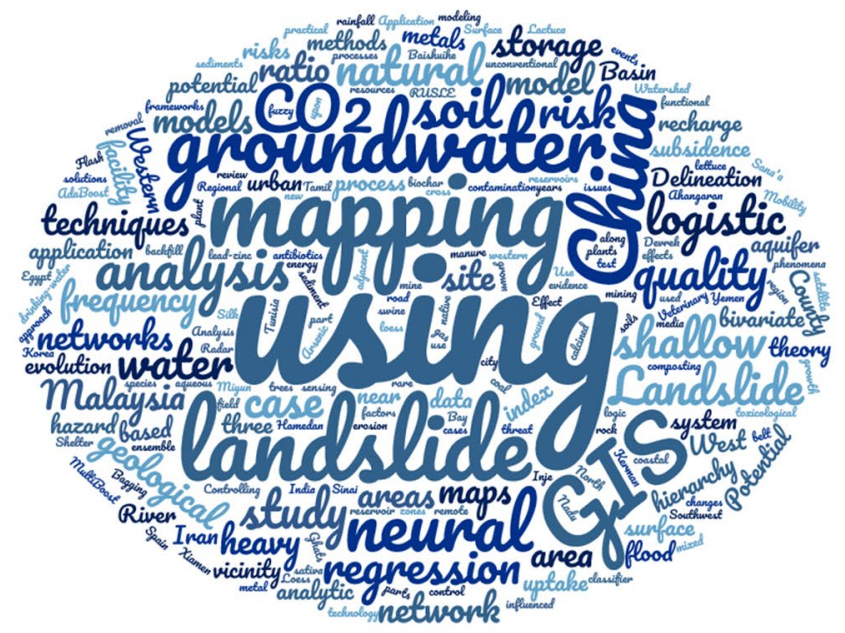

(c) from 2009 (start of EES)

Fig. 2 "Wordle" of the 50 most cited papers from various time periods (using Wortwolken ${ }^{T M}$ ) via http://www.wortwolken.com/

The Editors are pleased to award the most cited EES papers. Papers are listed in the references including the number of citations in the "Web-of-Science" $(\mathrm{WoS})^{2}$ and in the SCOPUS data base ${ }^{3}$ (the citation count is as of 23.12.2019):

1. Shirzadi et al. (2017) (highly cited paper).

2. Lai et al. (2017) (highly cited paper).

3. Li et al. (2017) (highly cited paper).

4. Wu et al. (2017).

5. Hong et al. (2017).

6. Adimalla and Venkatayogi (2017).

7. Wollschläger et al. (2017).

8. Razavizadeh et al. (2017).
9. Wu et al. (2017).

10. Raheli et al. (2017).

11. Shirzadi et al. (2017).

12. Barzegar et al. (2017).

13. Okoli et al. (2017).

14. Pham et al. (2017).

15. Bloise et al. (2017).

The first three works belong to highly cited papers in the field of environmental sciences ${ }^{4}$ Of these, EES has a total of eleven highly cited papers in the field. Our congratulations

\footnotetext{
${ }^{4}$ As of December 2017, these highly cited papers received enough citations to place them in the top $1 \%$ of their academic fields based on a highly cited threshold for the field and publication year.
}

\footnotetext{
2 https://webofknowledge.com/.

${ }^{3}$ https://www.scopus.com.
} 


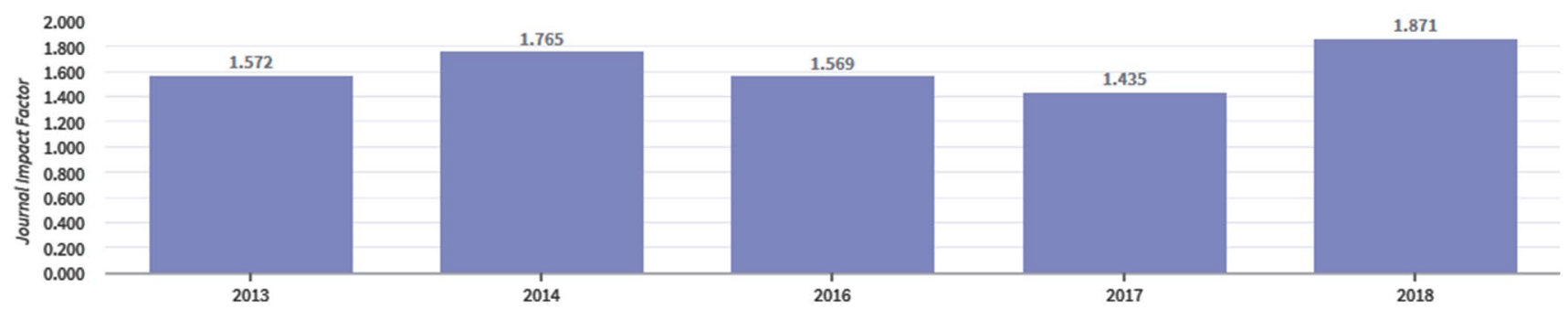

Fig. 3 EES impact factor development (Source: Clarivate Analytics)

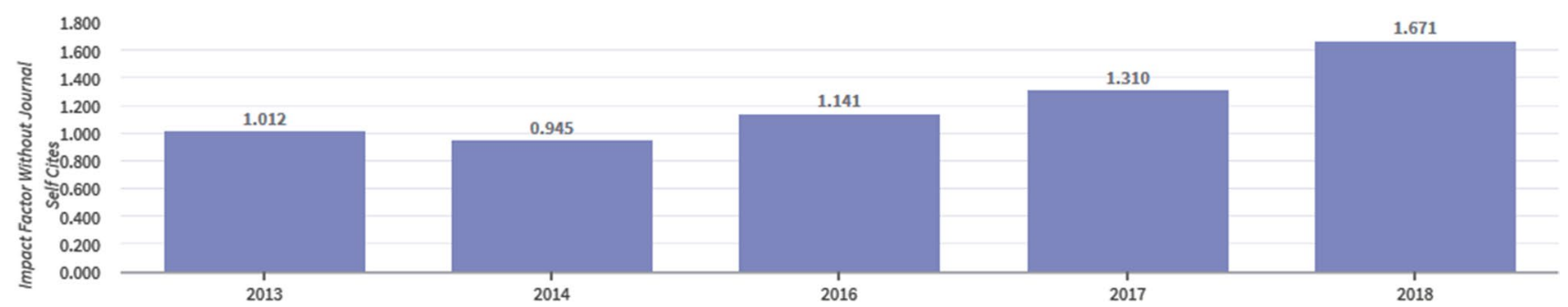

Fig. 4 EES impact factor without self-citations (Source: Clarivate Analytics)

go to these most cited papers, but also to all EES authors for their excellent contributions to the journal.

\section{Progress report}

In addition to the most cited paper awards, this editorial also provides more context of the journal's development in the current year.

\section{Impact factor development}

Starting with the impact factor development since 2012, Figs. 3 and 4 depict these with and without self-citations, respectively.

The impact factor varies between 1.435 and 1.871 , with the highest IF 2018 (Fig. 3). For 2019, we expect for the first time an impact factor above 2 . The impact factor without self-citations shows a continuous growth, which underlines the increasing awareness of EES publications also outside the journal itself. Self-citations in 2019 decreased to $978 \%$, the overall self-citation percentage (over all years) is equal to $1628 \%$; 601,829 EES articles were downloaded in 2018 .

\section{Authors' contributions}

In regard to authors' contributions we look at publications by countries and by institutions from 2017 until now. Fig. 5 depicts the 25 most frequent citizenships of the corresponding authors. China is leading with 742 published items, followed by a second grouping of authors from India, Iran,
USA, and Germany with more than 100 publications. The third group with a similar portion provides about $60 \%$ of published items. We also observe an increasing number of publications from Africa (Egypt, Nigeria) and Latin America (Argentina, Mexico).

According to the countries' analysis (Fig. 6), Chinese institutions are leading the publications by affiliations record (Chinese Academy of Sciences (CAS) the largest research organization worldwide with its own university, China University of Mining and Technology, China University of Geosciences) etc., followed by the Indian Institute of Technology. Several national research institutions from Germany, Argentina, France, and Italy are strongly contributing to the journal which emphasizes the importance of EES for strategic research topics. A third group is formed by several universities from Iran (Teheran, Shiraz, Tabriz).

\section{Submissions and publishing}

EES has been smoothly transferred to continuous article publishing (CAP) in 2016 which has significantly accelerated the publication process. Currently it takes an average of 51 days from submission to first decision. Please note that these are average numbers, specific cases may take a different time particularly when reviewers are difficult to find. Missing reviewers' attraction is also indicating that the particular manuscript may not fully fit into the scope of the journal. In such cases, implemented transfer option is used in order to avoid unacceptable review periods. The transfer desk is able to quickly offer more suited journals to the authors. 


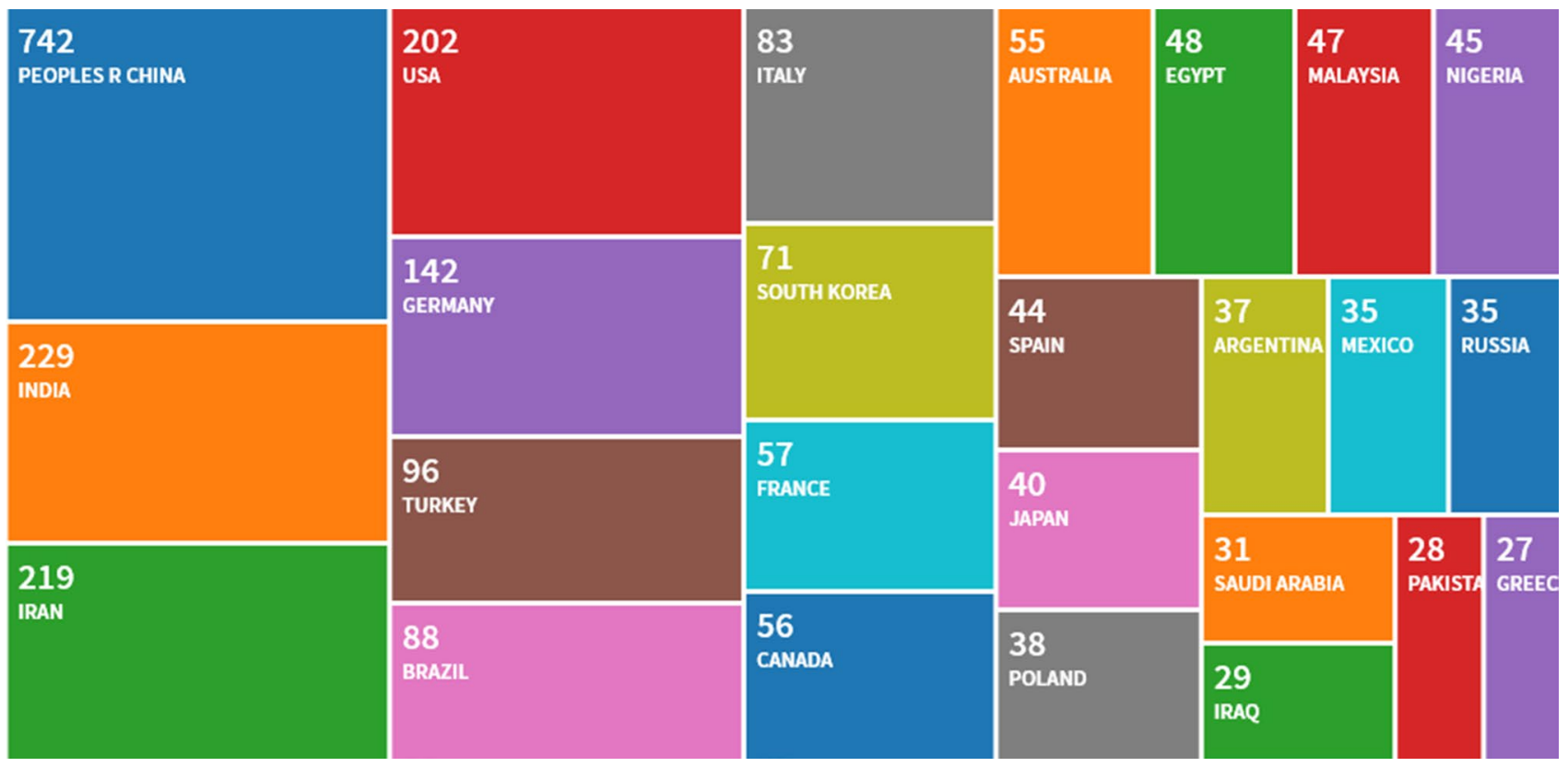

Fig. 5 EES publications by countries 2017-2019 (Source: Clarivate Analytics) (27-Greece, 28-Pakistan)

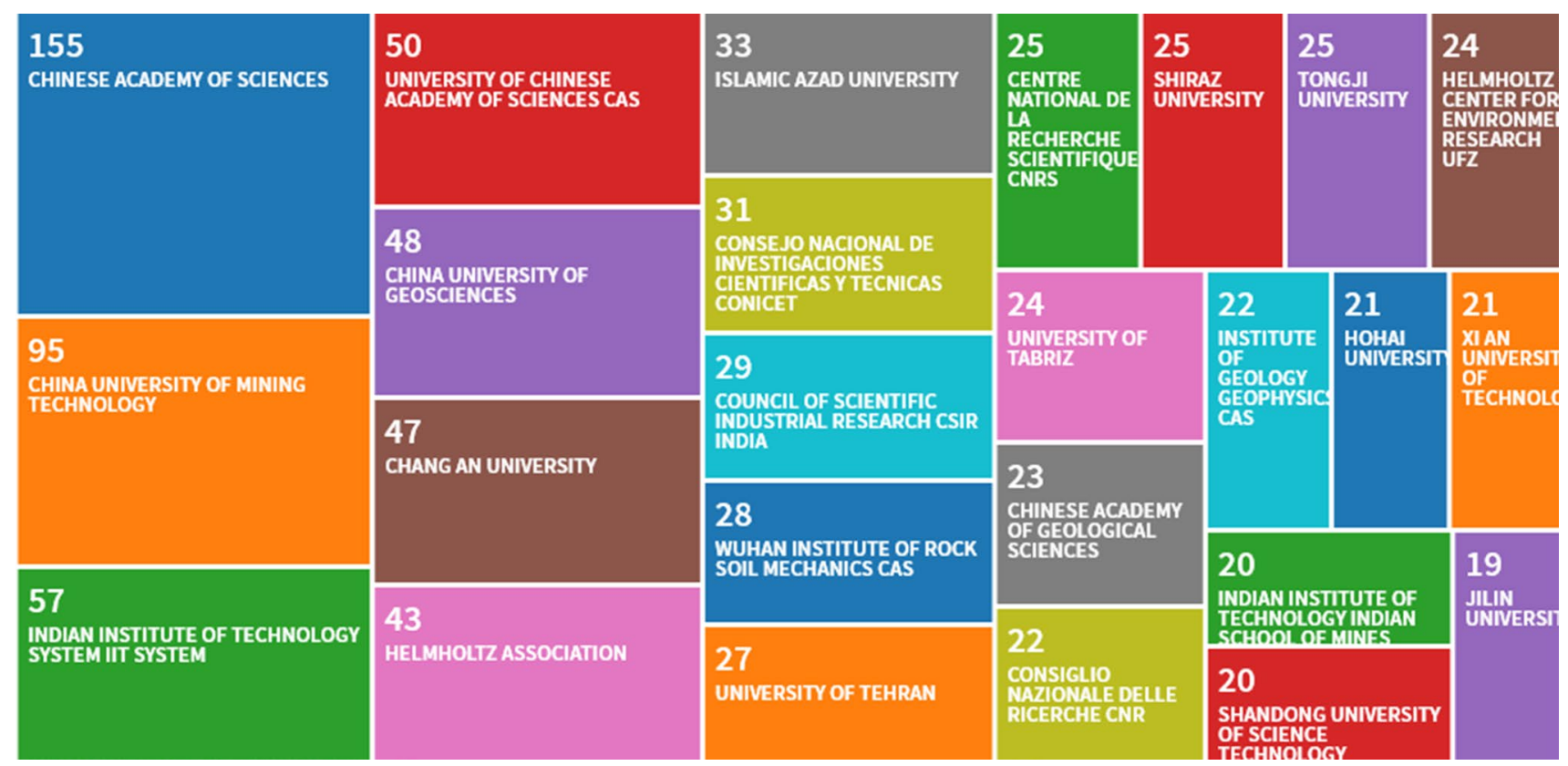

Fig. 6 EES publications by affiliations 2017-2019 (Source: Clarivate Analytics)

In 2018 the number of submissions exceeded 3000 for the first time which demonstrates the efforts for handling the journal. Figure 7 illustrates the increasing number of submissions and published articles in relation. Figure 8 shows the percentages of accepted versus rejected items (please note that manuscript transfers are not taken into account here).
Finally, the relation between published articles and citations is depicted in Fig. 9. This illustration underlines the increasing citation rate of EES articles (please note that this relation is not equivalent with the impact factor). 
Fig. 7 Submitted versus published items (Source: EES Editorial Manager)

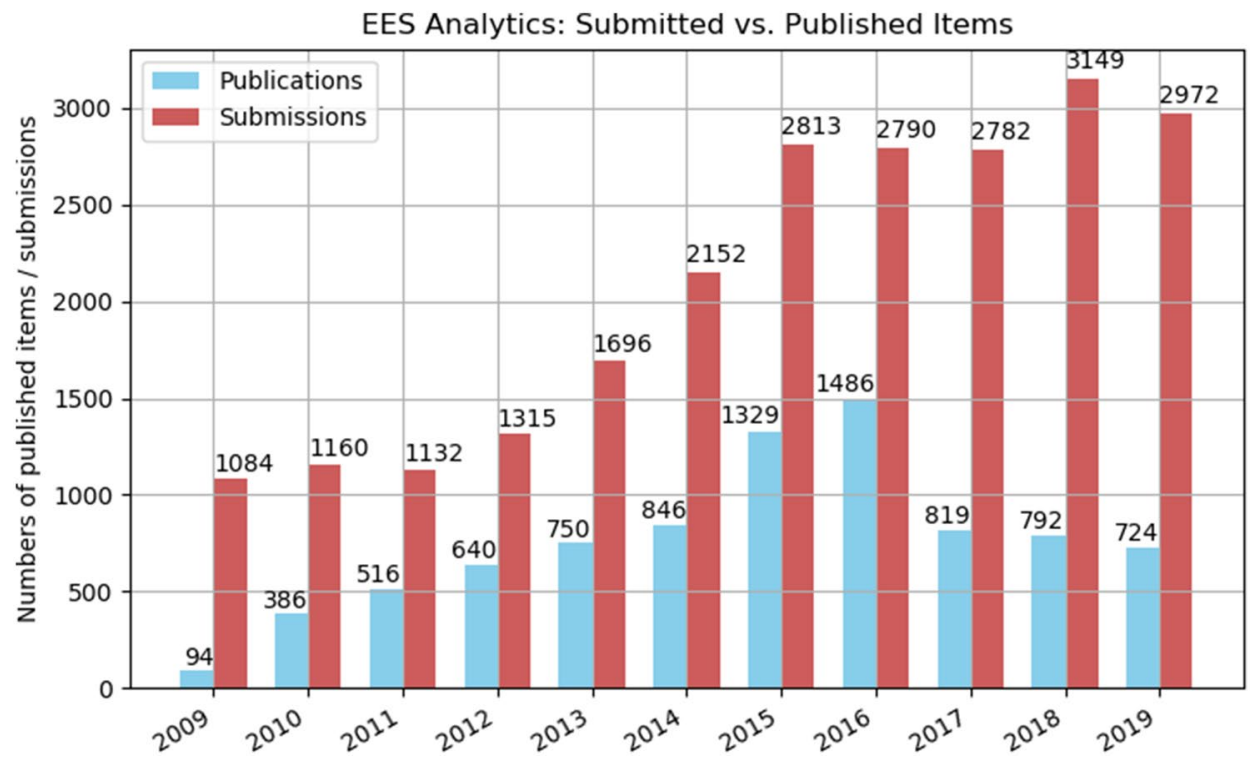

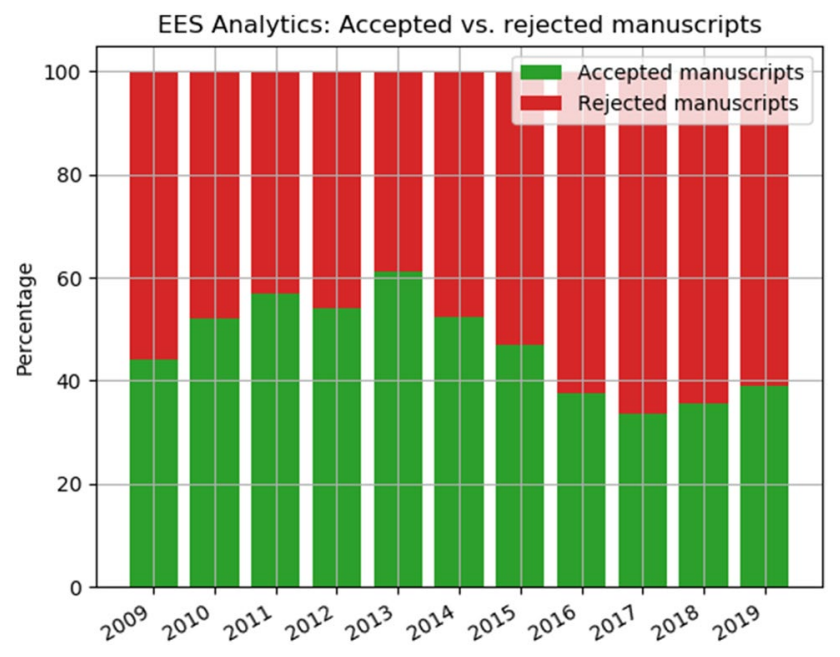

Fig. 8 Accepted versus rejected items (Source: EES Editorial Manager)

\section{Topical collections}

Topical collections have become a "trademark" of the journal. They are strategic instruments to foster important and new research themes. Topical collections are open in general and readers are encouraged to participate in these structured publication projects. A complete list of topical collections including ongoing is as follows (number of contributions is given in brackets):

\section{Topical collections 2018/2019 (sorted by published items, closed for submission)}

- Stone in architectural heritage (40)

- Subsurface energy storage II (31)

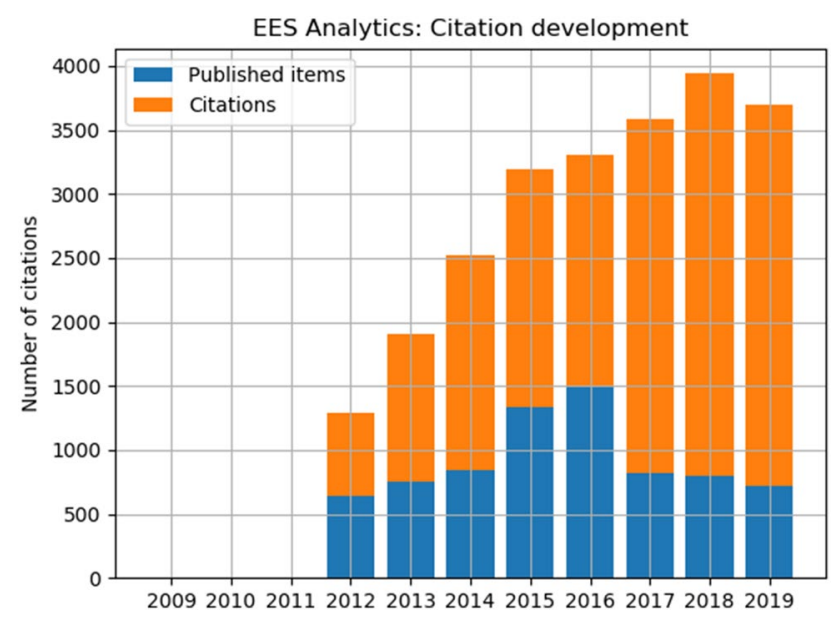

Fig. 9 Citations versus published items (Source: Clarivate Analytics) [Status 09.02.2020], the number of citations for last year normally is still increasing until spring of the ongoing year

- Water in loess (24)

- Environmental research of the three Gorges reservoir (21)

- Climate effects on water resources (15)

- NovCare-novel methods for subsurface characterization and monitoring: from theory to practice (14)

- Engineering problems in Karst (13)

- 4RAGSU (13)

- Karst hydrogeology: advances in Karst collapse studies (11)

- Learning from spatial data (11) 


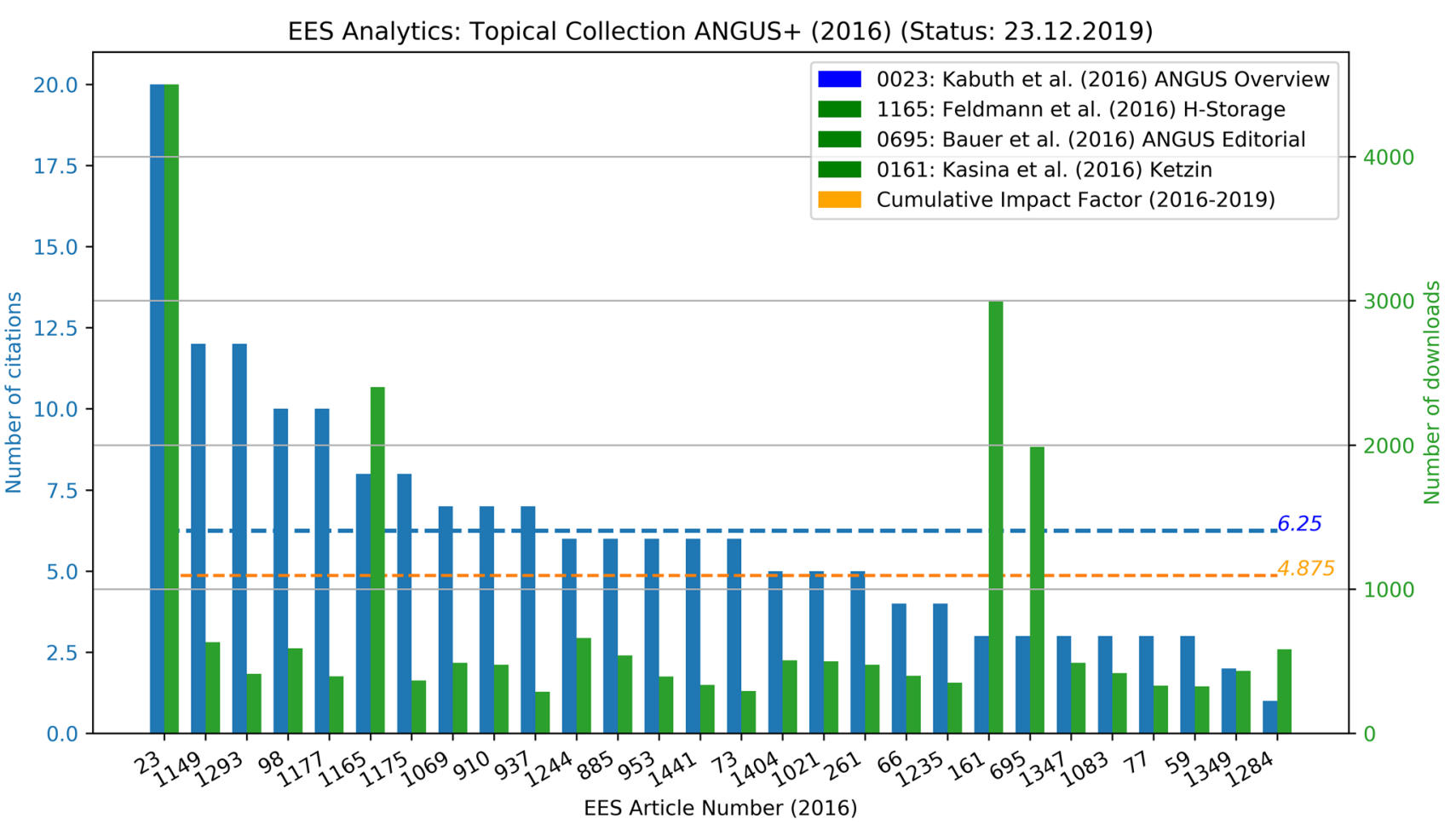

Fig. 10 ANGUS topical collection on subsurface energy storage (edited by Sebastian Bauer, Andreas Dahmke)

\section{Open topical collections (alphabetically)}

- Characterization, modeling, and remediation of Karst in a changing environment (Zexuan $\mathrm{Xu}$, Nicolas Massei, Ingrid Padilla, Andrew Hartmann and Bill $\mathrm{Hu}$ )

- Impacts of global change in groundwater in Western Mediterranean countries (Maria Luisa Calvache, Carlos Duque and David Pulido-Velazquez)

- Groundwater resources and sustainability (Nam C. Woo, Xiaosi Su, Kangjoo Kim and Yu-Chul Park)

- Groundwater resources in a changing environment (Okke Batelaan, Fabien Magri and Martin Sauter)

- Mineral and thermal waters (Adam Porowski, Nina Rman and Istvan Forizs)

- NovCare-novel methods for subsurface characterization and monitoring: from theory to practice (Uta Sauer and Peter Dietrich)

- Sustainable management of Karst natural resources (Sasa Malinovic and Zoran Stevanovic)

- Sustainable utilization of geosystems (Ulf Hünken, Peter Dietrich, Olaf Kolditz)

- Visual data exploration (Karsten Rink, Roxana Bujack, Stefan Jänicke, and Dirk Zeckzer)

- Water sustainability: a spectrum of innovative technology and remediation methods (Derek Kim, Kwang-Ho Choo, Jeonghwan Kim)

- Water in large basins (Peiyue Li and Jianhua Wu)
Contributions to topical collections belong to the most cited EES papers. A more detailed analysis is provided in Fig. 10 for the thematic issue on "Subsurface Energy Storage". The yellow line represents a cumulative impact factor of EES (i.e. summing up IFs from 2016 to 2018). The blue line indicates the contribution of the topical collection to the impact factor, i.e. mean value of citations of all related papers for the same period.

The list of open topical collections can be found at: https://www.springer.com/journal/12665/updates/17856 126.

Acknowledgements The success of EES is the result of team-work. This includes all contributors to the value chain of the journal. We thank the authors for their scientific contributions and sharing their knowledge with the community. We are grateful to the reviewers for their voluntary support and helping the authors to amend their research work so as to present it best. Associate Editors, Guest Editors and Editorial Board members are the scientific drivers and set the footprint for a unique journal. We explicitly include the Publisher's Team in Heidelberg and in Chennai for providing a fruitful and stable environment for the publication project. To honor the authors, SpringerNature is making free access to the most cited papers in EES for one month. As a reward for our reviewers, Springer Nature participated in a charity initiative, 'Filter of Hope'(https://www.springernature.com/gp/group /responsible-business/filter-of-hope). Water filters were provided to people in developing countries to gain access to safe drinking water in 2017 and 2018 on behalf of the valued reviewers for their completed peer reviews. The household filters remove microorganisms, protozoa and cysts from contaminated water. 


\section{References}

Adimalla N, Venkatayogi S (2017) Mechanism of fluoride enrichment in groundwater of hard rock aquifers in Medak, Telangana State, South India. Environ Earth Sci 76:1 (cited by 41/31)

Barzegar R, Moghaddam A, Tziritis E, Fakhri M, Soltani S (2017) Identification of hydrogeochemical processes and pollution sources of groundwater resources in the Marand plain, northwest of Iran. Environ Earth Sci 76:7 (cited by 27/24)

Bloise A, Catalano M, Critelli T, Apollaro C, Miriello D (2017) Naturally occurring asbestos: potential for human exposure, San Severino Lucano (Basilicata, Southern Italy). Environ Earth Sci 76:19 (cited by 23/20)

Hong H, Liu J, Zhu A-X, Shahabi H, Pham B, Chen W, Pradhan B, Bui D (2017) A novel hybrid integration model using support vector machines and random subspace for weather-triggered landslide susceptibility assessment in the Wuning area (China). Environ Earth Sci 76:19 (cited by 41/35)

Kharaka Y, Thordsen J, Kakouros E, Ambats G, Herkelrath W, Beers S, Birkholzer J, Apps J, Spycher N, Zheng L, Trautz R, Rauch $\mathrm{H}$, Gullickson K (2010) Changes in the chemistry of shallow groundwater related to the 2008 injection of $\mathrm{CO}_{2}$ at the ZERT field site, Bozeman, Montana. Environ Earth Sci 60(2):273-284 (cited by 181)

Kolditz B, Dörhöfer G, LaMoreaux J, Kolditz O (2018) Environmental earth sciences-most cited papers: 2015-2016: EES progress report 2017. Environ Earth Sci 77:8 (cited by 2)

Kühn M, Tesmer M, Pilz P, Meyer R, Reinicke K, Förster A, Kolditz O, Schäfer D (2012) CLEAN: Project overview on $\mathrm{CO}_{2}$ large-scale enhanced gas recovery in the Altmark natural gas field (Germany). Environ Earth Sci 67(2):311-321 (cited by 35)

Lai J, He S, Qiu J, Chen J, Wang L, Wang K, Wang J (2017) Characteristics of seismic disasters and aseismic measures of tunnels in Wenchuan earthquake. Environ Earth Sci 76:2 (cited by 60/59)

Li P, Qian H, Zhou W (2017) Finding harmony between the environment and humanity: an introduction to the thematic issue of the Silk Road. Environ Earth Sci 76:3 (cited by 57/58)

Liu H, Hou Z, Were P, Gou Y, Sun X (2014) Simulation of $\mathrm{CO}_{2}$ plume movement in multilayered saline formations through multilayer injection technology in the Ordos Basin, China. Environ Earth Sci 71(10):4447-4462 (cited by 37)

Okoli C, Diagboya P, Anigbogu I, Olu-Owolabi B, Adebowale K (2017) Competitive biosorption of $\mathrm{Pb}$ (II) and $\mathrm{Cd}(\mathrm{II})$ ions from aqueous solutions using chemically modified moss biomass (Barbula lambarenensis). Environ Earth Sci 76:1 (cited by 27/19)

Pham B, Tien Bui D, Prakash I, Nguyen L, Dholakia M (2017) A comparative study of sequential minimal optimization-based support vector machines, vote feature intervals, and logistic regression in landslide susceptibility assessment using GIS. Environ Earth Sci 76:10 (cited by 25/19)

Raheli B, Aalami M, El-Shafie A, Ghorbani M, Deo R (2017) Uncertainty assessment of the multilayer perceptron (MLP) neural network model with implementation of the novel hybrid MLP-FFA method for prediction of biochemical oxygen demand and dissolved oxygen: a case study of Langat River. Environ Earth Sci 76:14 (cited by 30/27)

Razavizadeh S, Solaimani K, Massironi M, Kavian A (2017) Mapping landslide susceptibility with frequency ratio, statistical index, and weights of evidence models: a case study in northern Iran. Environ Earth Sci 76:14 (cited by 33/32)

Senger K, Tveranger J, Braathen A, Olaussen S, Ogata K, Larsen L (2015) $\mathrm{CO}_{2}$ storage resource estimates in unconventional reservoirs: insights from a pilot-sized storage site in Svalbard, Arctic Norway. Environ Earth Sci 73(8):3987-4009 (cited by 18)

Shirzadi A, Bui D, Pham B, Solaimani K, Chapi K, Kavian A, Shahabi H, Revhaug I (2017) Shallow landslide susceptibility assessment using a novel hybrid intelligence approach. Environ Earth Sci 76:2 (cited by 73/62)

Shirzadi A, Chapi K, Shahabi H, Solaimani K, Kavian A, Ahmad B (2017) Rock fall susceptibility assessment along a mountainous road: an evaluation of bivariate statistic, analytical hierarchy process and frequency ratio. Environ Earth Sci 76:4 (cited by 29/25)

Wollschläger U, Attinger S, Borchardt D, Brauns M, Cuntz M, Dietrich P, Fleckenstein J, Friese K, Friesen J, Harpke A, Hildebrandt A, Jäckel G, Kamjunke N, Knöller K, Kägler S, Kolditz O, Krieg R, Kumar R, Lausch A, Liess M, Marx A, Merz R, Mueller C, Musolff A, Norf H, Oswald S, Rebmann C, Reinstorf F, Rode M, Rink K, Rinke K, Samaniego L, Vieweg M, Vogel H-J, Weitere M, Werban U, Zink M, Zacharias S (2017) The Bode hydrological observatory: a platform for integrated, interdisciplinary hydroecological research within the TERENO Harz/Central German Lowland Observatory. Environ Earth Sci 76:1 (cited by 34/31)

Wu J, Wang L, Wang S, Tian R, Xue C, Feng W, Li Y (2017) Spatiotemporal variation of groundwater quality in an arid area experiencing long-term paper wastewater irrigation, northwest China. Environ Earth Sci 76:13 (cited by 42/42)

Wu J, Xue C, Tian R, Wang S (2017) Lake water quality assessment: a case study of Shahu Lake in the semiarid loess area of northwest China. Environ Earth Sci 76:5 (cited by 32/42)

Publisher's Note Springer Nature remains neutral with regard to jurisdictional claims in published maps and institutional affiliations. 